\title{
Conservation of Human and Mouse Natural Cytotoxic (NC) Cell and Tumor Necrosis Factor Alpha (TNF $\alpha$ ) Mediated Lysis
}

\author{
John L Collins ${ }^{1 *}$ and Alexander Kofman ${ }^{2}$ \\ ${ }^{1}$ Department of Biological Sciences, The University of Tennessee at Martin, TN, USA \\ ${ }^{2}$ Department of Biological \& Environmental Sciences, Troy University, AL, USA
}

*Corresponding author: John L Collins, Department of Biological Sciences, The University of Tennessee at Martin, Martin, TN, USA

\begin{tabular}{|c|c|}
\hline ARTICLE INFO & ABSTRACT \\
\hline Received: 幽 October 25, 2019 & A sequentially derived lineage was established, $\mathrm{N} \rightarrow \mathrm{I} \rightarrow \mathrm{C}$ (Normal cells $\rightarrow$ \\
\hline Published: 慧 October 31, 2019 & $\begin{array}{l}\text { Intermediate cells } \rightarrow \text { Cancer cells).In this lineage N-cells are not tumorigenic, I-cells } \\
\text { are tumorigenic only in immune compromised mice and C-cells are tumorigenic }\end{array}$ \\
\hline $\begin{array}{l}\text { Citation: John L Collins, Alexander Kof- } \\
\text { man. Conservation of Human and Mouse } \\
\text { Natural Cytotoxic (NC) Cell and Tumor Ne- } \\
\text { crosis Factor Alpha (TNF } \alpha \text { ) Mediated Ly- } \\
\text { sis . Biomed J Sci \& Tech Res 22(3)-2019. } \\
\text { BJSTR. MS.ID.003747. }\end{array}$ & 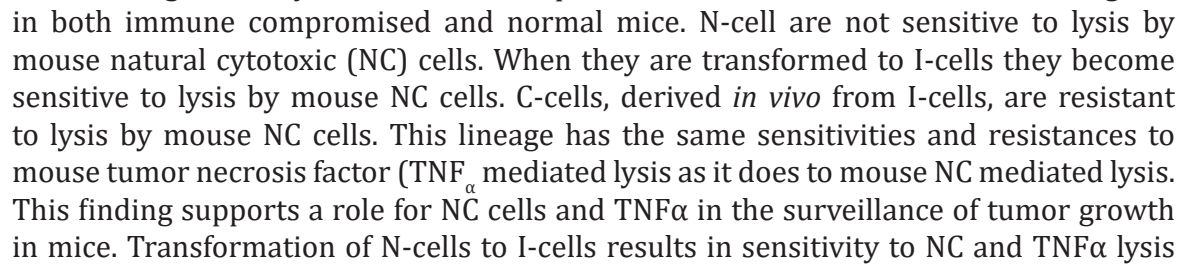 \\
\hline $\begin{array}{l}\text { Keywords: Natural Cytotoxic (NC) cells; } \\
\text { Tumor Necrosis Factor }(\mathrm{TNF} \alpha)\end{array}$ & $\begin{array}{l}\text { preventing the growth of I-cells in normal mice. C-cells escape surveillance by becoming } \\
\text { resistant to NC and TNF } \alpha \text { mediated lysis. This lineage of mouse cells also shows the same } \\
\text { sensitivities and resistances to human NC and human TNF } \alpha \text { mediated lysis as it does to } \\
\text { mouse NC and TNF } \alpha \text { mediated lysis. This finding supports a role for NC cells and TNF } \\
\text { in the surveillance of tumor growth in humans; a surveillance mechanism that has been } \\
\text { conserved in mice and humans for more than } 100 \text { million years. }\end{array}$ \\
\hline
\end{tabular}

\section{Introduction}

Normal, non-transformed, mouse cells (N-cells) do not grow as tumors in either normal or immune compromised (ATXFL) mice $[1,2]$. Intermediate cells (I-cells) derived from N-cells transformed and isolated in vitro are only capable of growth as tumors in immune compromised mice [1,2]. Cancer cells (C-cells) selected from I-cells in vivo are capable of growth as tumors in both immune compromised and normal mice [1,2]. This establishes a lineage $\mathrm{N}$ $\rightarrow \mathrm{I} \rightarrow \mathrm{C}$. N-cell are not sensitive to lysis by mouse natural cytotoxic (NC) cells $[3,4]$. When they are transformed to I-cells they become sensitive to lysis by mouse NC cells. Given that normal mice have NC cell activity and immune compromised mice do not have NC cell activity could explain why I-cells are capable of growth as tumors in immune compromised mice, but not in normal mice. Mouse I-cells selected in vivo for growth as tumors in both immune compromised and normal mice (C-cells) are resistant to lysis by mouse natural cytotoxic (NC) cells. Mouse N-cells are not sensitive to lysis mediated by mouse NC cells presumably because they are normal, non-transformed cells. Mouse I-cells, as a result of transformation become sensitive to lysis mediated by mouse NC cells, that is, they become sensitive to immune surveillance.

Mouse C-cells, have escaped immune surveillance by becoming resistant to lysis mediated by mouse NC cells, thus allowing them to grow as tumors in normal, as well as, immune compromised mice. These findings support a role for NC cells in the surveillance of tumor growth in mice. Mouse $\mathrm{N}$-cells are not capable of growing as tumors, even in immune compromised mice and are not sensitive 
to mouse NC activity. When N-cells are transformed to I-cells they become capable of growing as tumors in mice that do not have NC activity (immune compromised mice), but cannot grow as tumor in normal mice, which have NC activity. C-cells, because they are resistant to $\mathrm{NC}$ mediated lysis can grow as tumors not only in mice that do not have $\mathrm{NC}$ activity (immune compromised mice), but in mice that do have NC activity (normal mice). N-, I- and C-cells show an identical pattern of sensitivity to mouse tumor necrosis factor alpha $(\mathrm{TNF} \alpha)$ mediated lysis as they do to mouse NC mediated lysis. N-cells and C-cells are resistant to mouse TNF $\alpha$ mediated lysis while I-cells are sensitive [5]. This also supports a role for TNF $\alpha$ in the surveillance of tumor growth in mice. Here we show that mouse $\mathrm{N}-$, I- and C-cells also show the same pattern of sensitivity to human $\mathrm{NC}$ mediated lysis and to human TNF $\alpha$ mediated lysis as they do to mouse NC mediated lysis and to mouse TNF $\alpha$ mediated lysis. This finding indicates that human NC cells and human TNF $\alpha$ may play a role in tumor surveillance in humans. The fact that that the divergence of mice and human occurred approximately 110 million years ago [6] yet this tumor surveillance mechanism is conserved in these two species strongly suggests the importance of this tumor surveillance mechanism in the evolution of these two species.

\section{Materials and Methods}

\section{Mice}

Normal and immune compromised Balb/c mice were from the Salk Institute (La Jolla, CA) colony. Immune compromised mice were prepared by thymectomy of 4- to 6-week old mice followed 2 weeks later by lethal irradiation (750 rads) and reconstituted with 1-2 x 107 syngeneic fetal liver cells. (ATXFL).

\section{Cell Lines}

All cell lines were maintained in Dulbecco's Modified Eagles Medium (DMEM) plus 10\% fetal calf serum. The N-cell line is a cloned fibroblastic cell line derived from Balb/c fetal tissue [7]. The $\mathrm{N}$-cell line is incapable of growth in $0.3 \%$ agarose. The I-cell line was derived from the $\mathrm{N}$-cell line after treatment with 3-methylcholanthrene-11,12-dihydroepoxide in vitro. This transformed cell line was selected by growth in $0.3 \%$ agarose, then cloned. The C-cell line was isolated sequentially from a tumor that grew in ATXFL mice after the injection of the I-cell line. The cells from this tumor isolated from ATXFL mice were grown in vitro then injected into normal mice. The cells from the tumor that grew in normal mice were isolated and subsequently grown in vitro and cloned.

\section{Natural Cytotoxic (NC) Cells}

Normal Balb/c mice spleen cells from 8- to 10-week old mice were used as a source of mouse NC cells. Mouse spleens were dissociated in phosphate buffered saline, pH 7.2 and clumps allowed to settle at unit gravity. The suspended cells were collected, centrifuged at $200 \mathrm{x}$ G for 10 min then suspended in Roswell Park Memorial Institute 1640 medium (RPMI-1640) plus 10\% fetal calf serum. Normal human peripheral blood monocytes (approximately $90 \%$ monocytes and $10 \%$ lymphocytes were obtained from donors ranging in age from 25- to 45 years old. Blood was collected in tubes containing EDTA as an anticoagulant. Monocytes were separated from whole blood using Sepracell-MN (Sepratech Corp., Oklahoma City, OK), centrifuged $200 \times$ G for $10 \mathrm{~min}$. then suspended in RPMI1640 plus $10 \%$ fetal calf serum.

\section{Tumor Necrosis Factor Alpha (TNF $\alpha$ )}

Human recombinant TNF and mouse recombinant TNF $\alpha$ were kind gifts of Dr. L. Lin of the Cetus Corp. (Emeryville, CA) and was diluted in RPMI-1640.

\section{In Vitro Assay of Cytolysis}

The ability of human and mouse NC cells as well as the ability of human and mouse TNF $\alpha$ to lyse mouse N-, I- or C-cells was determined using the lactate dehydrogenase (LDH) cytotoxicity detection kit (Takara Products, Japan). The percentage of cytotoxicity was calculated as $100 \times$ ([experimental release] [spontaneous release])/ ([maximal release] - [spontaneous release]). Spontaneous release was determined in the presence of medium alone while the maximal release was determined in the presence of medium containing 1\% Triton X-100.

\section{Results}

As shown in Figure 1, when normal mouse cells (N-cells) are transformed in vitro to tumorigenic cells that are capable of growth as tumors only in immune compromised mice (I-cells), concurrent with transformation is the acquisition of sensitivity to mouse NC activity. Given that normal mice express NC activity and that immune compromised mice do not express $\mathrm{NC}$ activity, this result strongly suggests that the reason that I-cells are not capable of growth as tumors in normal mice is that the expressed NC activity of normal mice prevents the growth of I-cells as tumors in normal mice; that is, NC activity functions as a tumor surveillance system. Consistent with this hypothesis is the fact that when I-cells escape surveillance and grow as tumors in normal mice as well as immune compromised mice (C-cells) they become resistant to NC activity. It is likely that they grow as tumors in normal mice because they are resistant to $\mathrm{NC}$ mediated lysis.

There is some evidence that mouse NC activity is mediated by $\mathrm{TNF} \alpha$ [8] and it is not surprising that mouse $\mathrm{N}$-cells are not sensitive to lysis by mouse $\mathrm{TNF} \alpha$. When $\mathrm{N}$-cells are transformed to I-cells they become sensitive to mouse TNF $\alpha$ and when I-cells become C-cells they are resistant to lysis by mouse TNF $\alpha$. This is shown in Figure 2. These results demonstrate a strong relationship between mouse NC activity and mouse TNF $\alpha$ activity for the lysis of mouse I-cells. Interestingly, as shown in Figure 3, mouse N- and $\mathrm{C}$-cells are resistant to lysis by human NC cells, as they are to mouse NC mediated lysis. Further, mouse I-cells are sensitive to human NC mediated lysis, as they are to mouse NC mediated lysis. This 
suggests the human NC activity may play a role in surveillance human tumors. Further support of the relationship between NC activity and TNF $\alpha$ is shown in Figure 4. Mouse N- and C-cells are resistant to lysis by human $\mathrm{TNF} \alpha$, as they are to mouse $\mathrm{TNF} \alpha$ lysis. Mouse I-cells are sensitive to human TNF $\alpha$ mediated lysis, as they are to mouse TNF $\alpha$ mediated lysis.

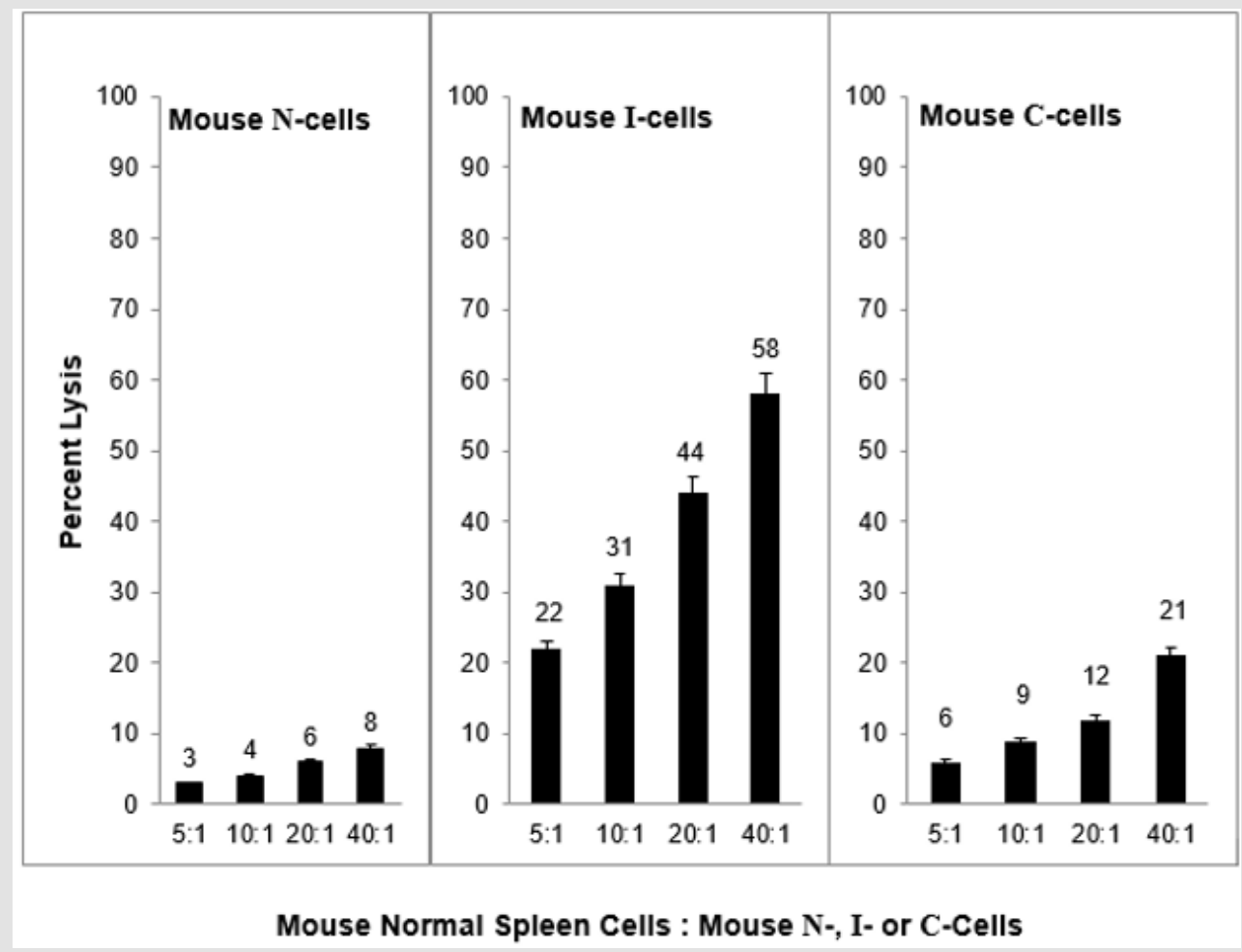

Figure 1: Mouse natural cytotoxic (NC) cell mediated lysis of mouse N-, I- and C-cells.

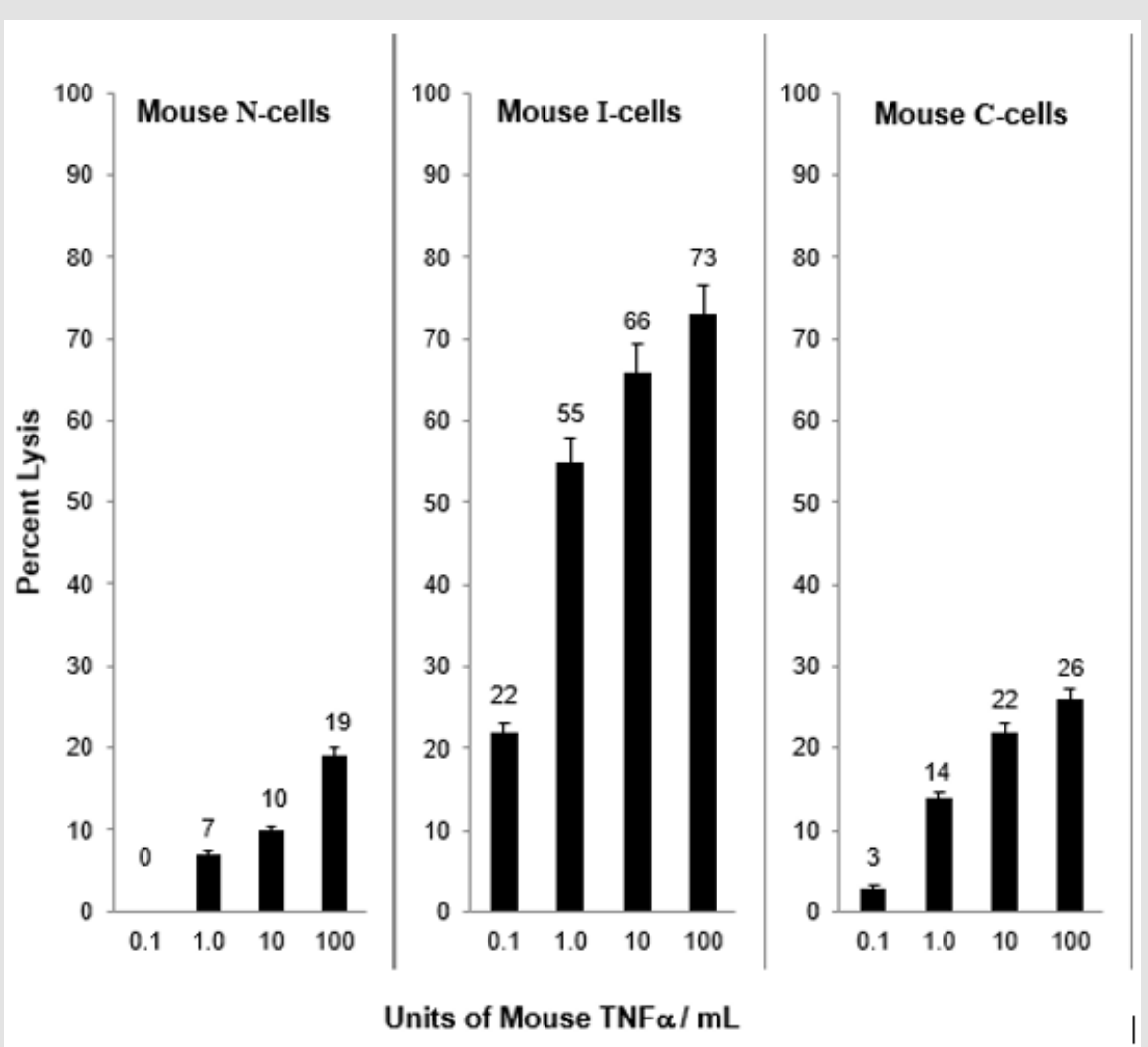

Figure 2: Mouse TNF $\alpha$ mediated lysis of mouse N-, I- and C-cells. 


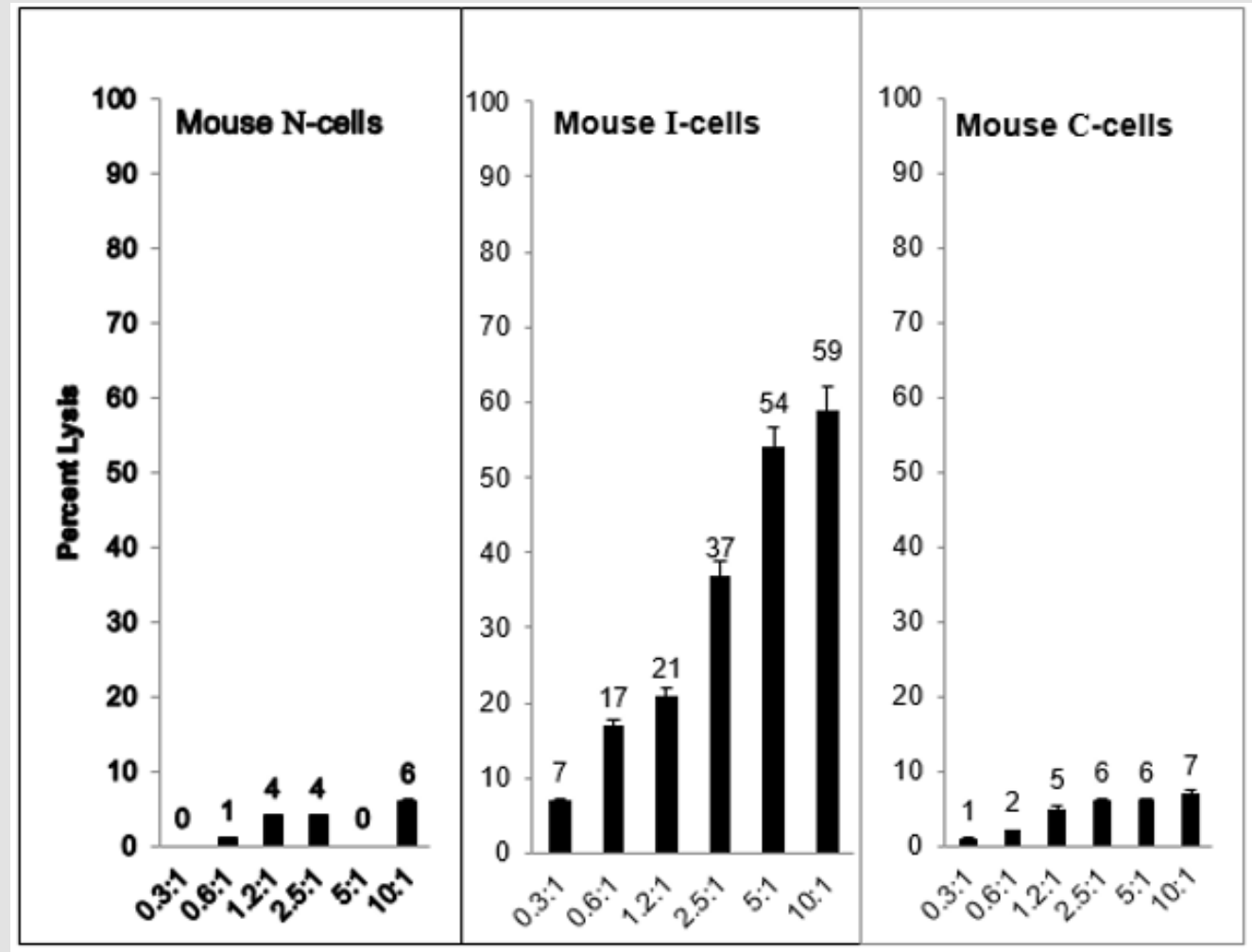

Human Monocytes : Mouse N-, I- and C-Cells

Figure 3: Human natural cytotoxic (NC) cell mediated lysis of mouse N-, I- and C-cells.

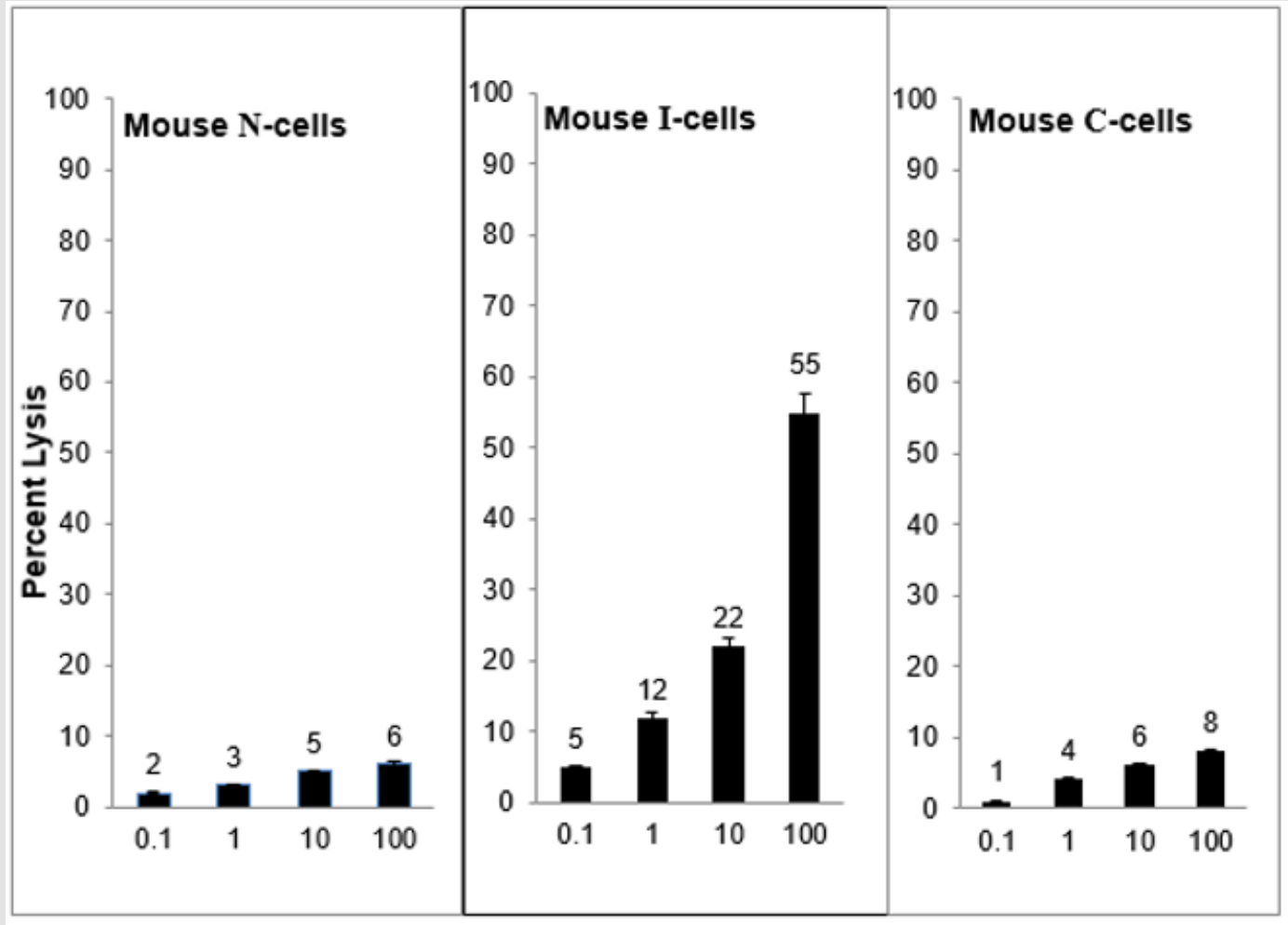

Units of Human TNF $\alpha / \mathrm{mL}$

Figure 4: Human TNF $\alpha$ mediated lysis of mouse N-, I- and C-cells. 


\section{Discussion}

Although there is clear evidence that humans who are at least partially immune compromised are a greater risk for developing some types of cancer [9-12]. If human do, in fact, have an antitumor immune surveillance mechanism one could argue that the only reason we ever see tumors in humans is because these tumorigenic cells have escaped immune surveillance. It is possible that tumorigenic cells arise in humans at a high rate, but because these initial tumor cells are sensitive to immune surveillance, we never see them as observable tumors. Thus, the only tumors we can diagnose would be composed of cells that have escaped an antitumor surveillance mechanism. In contrast to humans we can identify a tumor surveillance mechanism in mice [2]. The fact that some cells transformed in vitro can grow as tumors in immune compromised (ATXFL) mice but cannot grow as tumors in normal mice (I-cells) strongly supports the existence of an antitumor immune surveillance mechanism in mice. When these cells escape this antitumor surveillance mechanism they can grow as tumors in normal mice just as human tumors might grow in normal humans.

The fact that human NC cells and human TNF $\alpha$ are both capable of lysing mouse I-cells and not mouse C-cells strongly suggests that humans may use NC cells and TNF $\alpha$ as antitumor surveillance mechanisms. It is not easy to identify antitumor surveillance mechanisms in humans, especially if the only tumors we can identify are those that have escaped surveillance. For obvious reasons it is not possible to identify human I-cells. If we could we would potentially have more direct evidence as to what antitumor surveillance mechanism(s) it might be operating in humans. Until we can recognize human I-cells, the fact that this mechanism is conserved in mice and humans provides the strongest evidence of a mechanism for tumor surveillance in humans. It is somewhat surprising that human and mouse NC cells and TNF $\alpha$ both have specific recognition and lysis of mouse I-cells, given that these two species have been evolutionarily separated for more than one hundred million years. Thus, the functional activity of human and mouse NC cells and TNF $\alpha$ appears to be highly conserved. If these do represent antitumor surveillance mechanisms, the correlation between mouse and human NC cells and TNF $\alpha$ activity suggests that antitumor surveillance is very important to both species.

\section{Acknowledgement}

None.

\section{Conflict of Interest}

No conflict of interest.

\section{References}

1. Collins JL, Patek PQ, Cohn M (1982) In vivo surveillance of tumorigenic cells transformed in vitro. Nature 299(5879): 169-171.

2. Patek PQ, Collins JL, Cohn M (1978) Transformed cell lines susceptible or resistant to in vivo surveillance against tumorigenesis. Nature 276(5687): 510-511.

3. Patek PQ, Collins JL, Cohn M (1982) Activity and dexamethasone sensitivity of natural cytotoxic cell subpopulations. Cell Immunol 72(1): 113-121.

4. Patek PQ Collins JL, Cohn M (1983) Evidence that cytotoxic T cells and natural cytotoxic cells use different lytic mechanisms to lyse the same targets. Eur J Immunol 13(5): 433-436.

5. Patek PQ, Lin Y, Collins JL (1987) Natural cytotoxic cells and tumor necrosis factor activate similar lytic mechanisms. J Immunol 138(5): 1641-1646.

6. Kumar S, Hedges SB (1998) A molecular timescale for vertebrate evolution. Nature 392(6679): 917-920

7. Lin Y, Collins JL, Patek PQ Cohn M (1983) An analysis of the sensitivity of somatic cell hybrids to natural killer cell- and natural cytotoxic cellmediated lysis. J Immunol 131(3): 1154-1159.

8. Ortaldo JR, Mason LH, Mathieson BJ, Liang SM, Flick DA, et al. (1986) Mediation of mouse natural cytotoxic activity by tumour necrosis factor. Nature 321(6071): 700-702.

9. Gatti RA, Good RA (1971) Occurrence of malignancy in immunodeficiency diseases. A literature reviews. Cancer 28(1): 89-98.

10. Kersey JH, Spector BD, Good RA (1973) Immunodeficiency and cancer. Adv Cancer Res 18: 211-230.

11. Mortaz E, Tabarsi P, Mansouri D, Khosravi A, Garssen J, et al. (2016) Cancers Related to Immunodeficiencies: Update and Perspectives. Front Immunol 7: 365.

12. Salavoura K, Kolialexi A, Tsangaris G, Mavrou A (2008) Development of cancer in patients with primary immunodeficiencies. Anticancer Res 28(2B): 1263-1269.
ISSN: 2574-1241

DOI: 10.26717/BJSTR.2019.22.003747

John L Collins. Biomed J Sci \& Tech Res

This work is licensed under Creative Commons Attribution 4.0 License

Submission Link: https://biomedres.us/submit-manuscript.php

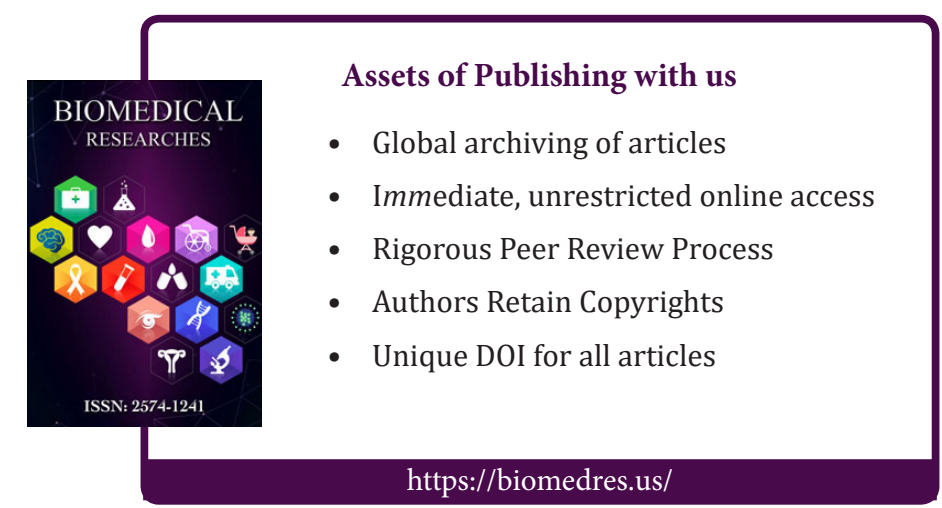

